This item was submitted to Loughborough's Research Repository by the author.

Items in Figshare are protected by copyright, with all rights reserved, unless otherwise indicated.

\title{
International water targets and national realities in Sub-Saharan Africa: the case of Uganda
}

PLEASE CITE THE PUBLISHED VERSION

https://doi.org/10.1080/21582041.2017.1393557

\section{PUBLISHER}

(C) Academy of Social Sciences. Published by Taylor and Francis

\section{VERSION}

AM (Accepted Manuscript)

\section{PUBLISHER STATEMENT}

This work is made available according to the conditions of the Creative Commons Attribution-NonCommercialNoDerivatives 4.0 International (CC BY-NC-ND 4.0) licence. Full details of this licence are available at: https://creativecommons.org/licenses/by-nc-nd/4.0/

\section{LICENCE}

CC BY-NC-ND 4.0

\section{REPOSITORY RECORD}

Sansom, Kevin, David Hirst, and Sam Kayaga. 2019. "International Water Targets and National Realities in Sub-saharan Africa: The Case of Uganda”. figshare. https://hdl.handle.net/2134/27980. 


\section{Contemporary Social Science}

Themed Issue on 'Sustaining natural resources in a changing environment' Guest editors: Linda Hantrais, Ruth Kattumuri \& Ashley Thomas Lenihan

\section{International water targets and national realities in Sub-Saharan Africa: the case of Uganda}

Kevin Sansom (corresponding author), Water, Engineering and Development Centre (WEDC), The John Pickford Building, School of Architecture, Building and Civil Engineering, Loughborough University, Leicestershire LE11 3TU, UK, 01509 222885, K.R.Sansom@lboro.ac.uk

David Hirst, c/o International Fertilizer Development Centre, P.O. Box 75391, Bugolobi, Kampala, Uganda, dhirst@ifdc.org

Sam Kayaga, Water, Engineering and Development Centre (WEDC), The John Pickford Building, School of Architecture, Building and Civil Engineering, Loughborough University, Leicestershire LE11 3TU, UK, 01509 222885, S.M.Kayaga@lboro.ac.uk

\section{Notes on contributors}

Kevin Sansom is a lecturer and programme manager at WEDC (Water, Engineering and Development Centre), in the School of Architecture, Building and Civil Engineering at Loughborough University, UK. He has undertaken strategic research, consultancy, and capacity development projects in the management of water and sanitation in Africa and Asia, for both the urban and rural sectors. He has extensive experience in programme monitoring and evaluation, sector reviews, institutional development, collaboration with non-state providers and water utilities management. He has had key roles on projects in more than 18 countries, over 25 years, working with development agencies, governments, NGOs and other stakeholders.

David Hirst completed his studies for an MSc in Water and Environmental Management, at the Water Engineering Development Centre, in the School of Architecture, Building and Civil Engineering of Loughborough University. He is a development practitioner with over ten years of project and staff management experience in water and sanitation, agricultural livelihoods and food security programmes in East and West Africa, including eight years working in Uganda. His main research area of interest is the sustainability of rural water systems with a particular focus on improved models of operation and maintenance.

Sam Kayaga is a chartered Water/Sanitation Engineer and Senior Lecturer in the School of Architecture, Building and Civil Engineering, Loughborough University. Prior to joining Loughborough University's Water, Engineering and Development Centre (WEDC) in 2002, he worked for eighteen years for the National Water and Sewerage Corporation (NWSC), Uganda's urban water utility. At Loughborough, he is involved in research, teaching and advisory services for sustainable water and sanitation services in middle- and low-income countries. His main areas of research are sustainable urban water and sanitation management and institutional capacity, with a special focus on extending services to the currently unserved. 


\title{
International water targets and national realities in Sub-Saharan Africa: the case of Uganda
}

\begin{abstract}
This article considers how to reconcile ambitious UN Sustainable Development Goals (SDGs) for universal piped water supplies with developing country realities in Sub-Saharan Africa. A concise process for effective reviews of medium-term national targets is proposed and is applied in an analysis of the current provision of piped water to households and shared community facilities in urban and rural settings in Uganda. Different disciplinary perspectives are adopted to review trends, the performance of key stakeholders and their scope for achieving new targets. Only about 5 per cent of households have piped water supplies on their premises in rural areas in Sub-Saharan Africa. To achieve the SDG target of 100 per cent coverage will therefore take a long time and requires continued support for the sustainability of community water facilities as a priority. The SDGs offer sensible long-term aims, but national medium-term target setting and reviewing remain critical and require realistic and systematic planning approaches, as well as careful global reporting of national performance against SDG targets. The authors argue that balanced incentives are needed to encourage stakeholders to strive for realistic targets in the medium term, without demotivating countries with limited capacities and resources.
\end{abstract}

Key words: Sustainable Development Goals, water targets, sector reporting, Sub-Saharan Africa

\section{Introduction}

As the transition between the Millennium Development Goals (MDGs) and the Sustainable Development Goals (SDGs) (2016-2030) is made, it is important to consider key strengths and weaknesses of the processes and consequences of the MDGs. The United Nations (UN) recognised that the MDG agenda promoted concrete actions to address human development shortfalls, provided a common framework, and improved coordination for development actors. However, the MDGs resulted in the setting of rather rigid national policy agendas, following international benchmarks rather than local conditions, often ignoring the complexities of the development process (UN, 2012, pp. 6, 7). In addition, even where water MDG targets were met by 2015, there are doubts about the extent to which the new facilities will be sustainably managed, particularly in rural areas.

The SDGs were developed following an exhaustive process of debates and negotiations (UNDESA, 2015, p. 1). Research evidence shows that, when the water, sanitation and hygiene (WASH) SDGs are eventually achieved, they will bring considerable and wideranging benefits (Hutton \& Chase, 2016, p. 20). Meanwhile, more needs to be known about the challenges that governments are facing in developing sustainable water services, and how SDG targets are going to be met.

During the MDG period up to 2015, households were counted as having access to potentially safe water sources if they used 'improved' water sources for individual households or shared sources that include hand-pumps or stand-posts. In Uganda, compliance with the 'improved water source' criteria included households within 1,000m (rural), whereas the SDG for 
drinking water (target 6.1) relates to water supply on the premises of all households (UNWater, 2016, pp. 12, 13), thereby considerably raising the bar for target achievement.

Only 5 per cent of households in rural Africa currently have piped water on their premises; most people rely on shared point water sources such as hand-pumps and public standposts (WHO/UNICEF, 2015, p. 77). The proportion rises to 10 per cent when other on-plot options such as boreholes are included. In urban Africa, where the economies of scale for piped water are more effective, the percentage of households with piped water on premises has only risen from 44 to 46 per cent since 2000 (WHO/UNICEF, 2017, p. 105). The SDGs are therefore overly ambitious, expecting a further 90 per cent of rural households to gain new on-plot water supplies by 2030.

The clear risk is that, if governments and international donors focus on SDG targets for onplot water solutions, they may neglect poorer rural areas where only shared water facilities, such as hand-pumps, are currently feasible. A key SDG objective is to 'leave no-one behind', which is a desirable equity objective, but many rural communities are poor, remote or vulnerable, and will struggle to develop and manage effective piped on-plot water systems, without extensive assistance from government and donors over a long period.

Uganda has been selected as a case study because of its good record in water sector performance and reforms (Water and Sanitation Program, World Bank, 2011, p. 15; WHO UNICEF, 2015, p. 75). In Uganda, the Ministry of Finance, Planning and Economic Development leads the process in developing medium-term plans that covers key sectors. For example, in 2017 the National Development Plan II was agreed for 2015-16 to 2019-20 (MFPED, 2017). The Plan is based on budget framework papers with, for instance, the Ministry of Water and Environment (MWE), and incorporates trends in performance, planning and budget forecasts. This process is enhanced through comprehensive annual water sector performance reporting and joint sector reviews. However, given the major shift in emphasis in the SDGs, as explained above, future medium-term plans and targets need to take into account critical analyses of key stakeholders' capacities and approaches. This issue is examined here and is also incorporated into a suggested framework for national water sector medium-term target setting.

\section{Assessments for water targets}

Water sector institutions in each country are required to balance their funding priorities and plans for meeting ambitious SDG targets and providing basic services to poor and hitherto unserved populations in a realistic and iterative way, bearing in mind absorptive capacity on a sustainable basis. The broader question addressed in this article is how to reconcile ambitious SDGs for universal piped or on-plot water supplies with developing country realities. This issue is examined considering the following research questions:

1. How has the Ugandan water sector performed in terms of service levels, equity and management aspects, and what are key reasons for the trends identified?

2. How have key types of rural and urban water sector stakeholders performed to date in Uganda, and to what extent are they likely to be able to achieve proposed SDG targets?

3. What are the implications of the SDG targets, considering challenges and opportunities for rural and urban water services in Uganda? 
4. How best can national governments develop and work towards realistic medium-term WASH targets, while addressing the longer term SDGs?

These questions are consistent within the broader framework for reviewing medium-term development targets at national level, as suggested in Figure 1. The research reported in this article is based on recent field research on the management of rural water supplies in Uganda, utilising previous urban water research conducted by two of the authors. A review of quantitative and qualitative data has also been conducted using the available literature on the subject and includes extensive grey literature, academic articles and UN publications.

Figure 1 - Reviewing medium-term national WASH development targets

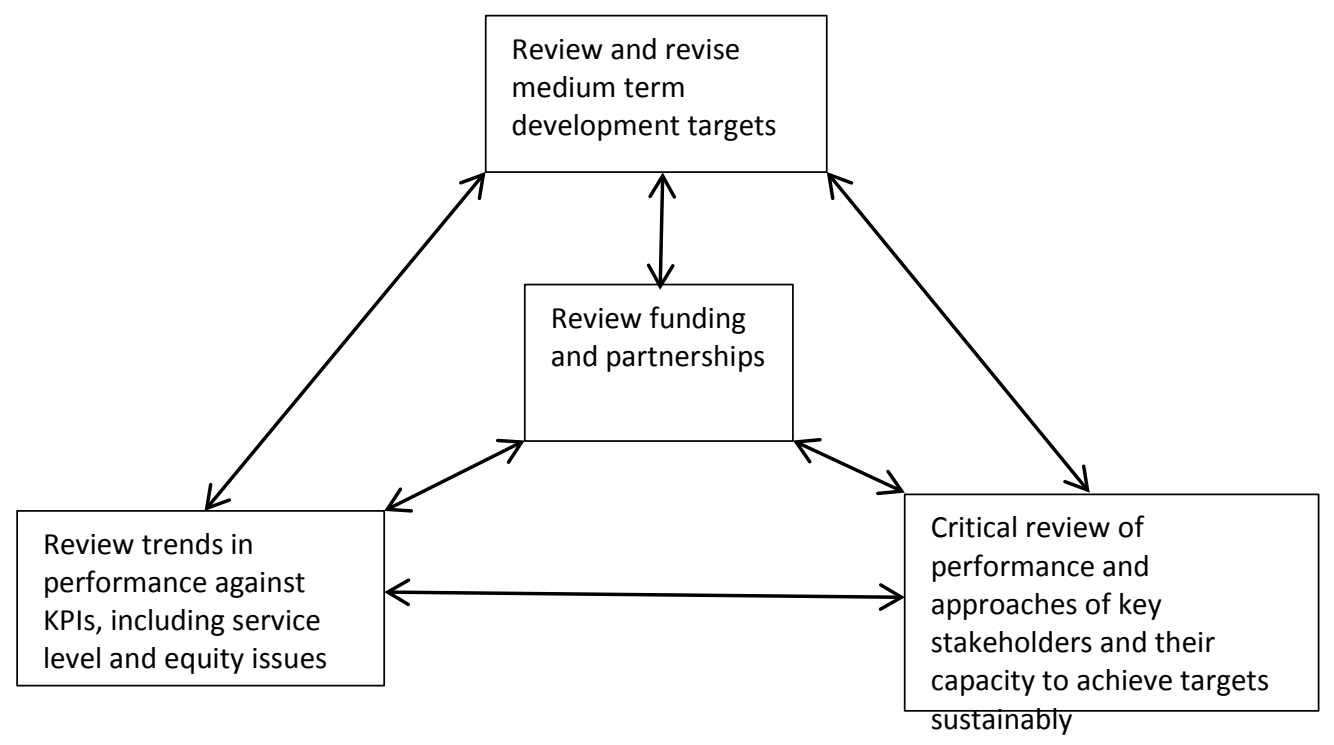

Source: The authors.

Note: $\mathrm{KPI}=$ Key Performance Indicators

Reed, Fraser, Morse \& Dougill (2006, p. 414) propose a rather complex 'adaptive learning process for sustainability indicator development and application'. Our aim is to suggest how the proposed targets can be periodically reviewed in terms of service levels in a specific national context. A concise overview process, such as the one shown in Figure 1, can be used by key national stakeholders in planning for improved WASH service provision. Some aspects shown in Figure 1 are not considered in detail, such as funding and partnerships. Without systematic reviews of medium-term targets, national governments may find that the gap between the ambitious SDG targets and what they can actually achieve on an annual basis leads to poorly focused plans.

SDG target 6.1, states: 'By 2030, achieve universal and equitable access to safe and affordable drinking water for all' (WHO, 2017 pp. 12, 13). Table 1 summarises what this means in terms of level of services for both the SDG target and the more basic MDGs.

The MDGs mainly relate to shared water sources, whereas, in order to meet the SDG target 6.1 threshold for a 'safely managed' service, the improved source must meet three conditions:

- the source should be located on premises (within the dwelling, yard or plot);

- $\quad$ water should be available when needed; 
- the water supplied should be free from faecal and priority chemical contamination.

Table 1. The new JMP ladder for household drinking water services in the SDG era.

\begin{tabular}{|l|l|l|}
\hline MDG/SDG & Service ladder & Progressive realisation \\
\hline SDG 6.1 & $\begin{array}{l}\text { Safely managed drinking } \\
\text { water }\end{array}$ & $\begin{array}{l}\text { Improved source located on premises, available } \\
\text { when needed, and free from faecal and priority } \\
\text { chemical contamination }\end{array}$ \\
\hline $\begin{array}{l}\text { MDG } \\
\text { continuity }\end{array}$ & Basic water & $\begin{array}{l}\text { Improved source within } 30 \text { minutes round-trip } \\
\text { collection time }\end{array}$ \\
\cline { 2 - 3 } & Limited water & $\begin{array}{l}\text { Improved source over } 30 \text { minutes round-trip } \\
\text { collection time }\end{array}$ \\
\cline { 2 - 3 } & Unimproved water & $\begin{array}{l}\text { Unimproved source that does not protect against } \\
\text { contamination }\end{array}$ \\
\cline { 2 - 3 } & No service & Surface water \\
\hline
\end{tabular}

Source: WHO, 2017, p. 12,13.

If any of the three conditions is not met, but the improved source is within 30 minutes of the home, it will continue to be categorised as a 'basic' service. 'Improved' sources are those that are potentially capable of delivering safe water by nature of their design and construction (WHO, 2017, pp. 12-13). Sustainability is a key concern in the rural sector, as can be seen from the Uganda case study. The WHO acknowledges that individual countries will need to consider how to balance support for extending access (MDGs) and to improve service levels (SDGs), (WHO, 2017, p. 13), which is difficult to achieve in situations where sector funding is limited.

SDG Target 6b) states: 'Support and strengthen the participation of local communities in improving water and sanitation management'. This is necessary to ensure that solutions decided upon are suitable for specific socioeconomic contexts and to encourage local ownership of the solutions when implemented to ensure sustainability over time (UNWater, 2016, p. 25).

Community involvement is an important part of such stakeholder participation. However, a growing body of evidence (Harvey, Uno, \& Reed, 2006, p. 183; Lockwood, Smits, Schouten, \& Moriarty 2010, p. 4) reveals the limitations and lack of sustainability of community management of water supplies in rural areas. In many African countries sustained efforts have been made to increase the involvement of the private sector, particularly in undertaking repairs of water facilities.

Equity of services 'implies progressive reduction and elimination of inequalities between population subgroups' (WHO, 2017, p. 11). Jarman (2016, p. 110) concluded that 'age, ethnicity and gender are still fundamental variables that together and separately contribute to differentiated social outcomes'. This observation clearly has relevance in rural Africa where 'Women and girls are responsible for water collection in 8 out of 10 households with water off their premises' (WHO, 2017, p. 30). The new SDG basic service level 'Improved source within 30 minutes round-trip collection time' and SDG target 6.1 shown in Table 1 should contribute to a significant reduction in the burdens on women and children. Ndesamburo, Flynn, \& French (2012, p. 453) highlight 'the need for equity and inclusion approaches to 
better understand and meet the water, sanitation, and hygiene (WASH) needs of women and girls, as well as other groups who are often excluded'.

Equity of service provision is taken here to mean the extent of use of basic and unimproved service levels and by wealth quintile in Uganda. National sector performance reporting in Uganda (MWE, 2016, pp. 26, 128) also regularly reviews equity issues by area-based variations in the distribution of community water points and by gender-based indicators, namely 'the percentage of water committees or boards with women holding key positions'.

\section{The Ugandan case study}

Multiple data sources were used in the case study, as part of a triangulation process. For the rural water field research, fifteen semi-structured interviews, five focus group discussions and observations were conducted on Hand Pump Mechanic Associations (HPMAs) in five districts, together with key informant interviews at national level. The selection of these research locations in Uganda was carefully considered against several criteria including: availability of data, presence and years of HPMA operation, and presence of alternative operation and maintenance (O\&M) models. The urban water research was based on a thorough review of the many government utility and consultancy reports in Uganda, building on previous research by the authors and the academic literature.

The three main parts of this section assess current progress and prospects for achieving the SDG water targets in Uganda, as set out in Figure 1. Firstly, we review piped water supplies to households, which are mostly found in urban areas; secondly, an assessment is made of shared community water facilities in rural areas, and thirdly, we review progress in achieving equity in the water sector.

\section{Piped water services and stakeholder capacities in Uganda}

The percentage of households in urban Uganda who have piped water supplies on their premises has steadily increased from 7 percent in 1990 to 23 per cent in 2015 (WHO \& UNCEF 2015, p. 75), despite a high annual population growth of over 3 per cent, a figure that supported by recent household surveys and the MWE 2016 sector performance report, but is higher than the coverage reported in the recently launched JMP report (WHO \& UNICEF, 2017a).

The National Water and Sewerage Corporation (NWSC), a public utility, is performing well in managing water services in the larger Ugandan towns against a number of indicators and ratios. For example, the number of customer pipe connections has increased from 152,138 in 2006 (MWE, 2006, p. 23) to 472,193 in 2016 (MWE, 2016, p. 45). NWSC is also maintaining good service levels, as is demonstrated by the customer satisfaction index at 88 per cent (MWE, 2016, p. 45). Other aspects include carefully managing customer relations, employing competent staff, while generating funds for investment. NWSC have also made good progress in enabling urban poor households, to access piped water services (MWE, 2016, p. 45; NWSC, 2015).

Despite these achievements, a number of challenges remain. The average Non-Revenue Water (NRW) in large towns, i.e. the percentage of water produced and not paid for, is 31.6 per cent (NWSC, 2015, p. 8), compared to a desirable level of 20 per cent (McIntosh, 2003, p. 
62). Note the NRW figures do not include households who are not connected to the piped water system. However, NWSC compares well with other utilities in Sub-Saharan Africa in terms of trends in performance: it was assessed as the second best performing national utility in 2013 (Van den Berg \& Danilenko, 2017, p. 47).

Currently, NWSC provides water services in 218 towns (see https://www.nwsc.co.ug/). The remaining towns are under the responsibility of the MWE through various Water Authorities and/or private operators. Of the towns under MWE, 60 do not have piped water supply (MWE, 2016, p. 32).

Private operators manage water supplies in few small towns in Uganda as part of formal management contracts (MWE, 2016, p. 32), while local governments oversee these contracts. Private operators have managed small town water services with some success, although providing incentives for new capital investments and paying for expansion of water services, with such short-term management contracts, has proved problematic, (Hirn, 2013, p. IV). Increasingly, NWSC has taken on the management of more small-town water supplies, but such towns have higher levels of NRW and poorer service levels (MWE, 2016, p. 53). NWSC staff reported in 2017 that they are effectively using a 'clustered approach' to managing small-town water services, whereby managers in larger towns are supporting staff managing water services in nearby smaller towns. However, those small town water systems are usually cross-subsidised by the larger town offices. Overall, Uganda has good capabilities for managing larger piped water systems effectively.

In considering the prospects for developing piped water services in rural areas, it is relevant to examine what is currently happening with piped supplies in these areas. 'Typically a user elected Water and Sanitation Committee (WSC) is responsible for the management of village piped water supply services and a local individual is hired for the operation of the scheme'. (Hirn, 2013, p. 6)

To achieve universal household piped water services, a key question emerges: Is there sufficient capacity and incentive to manage small rural piped water systems, where the economies of scale are considerably less, and affordability is more of an issue? Private operators or capable individuals would seem to have the potential to manage small rural systems in conjunction with local committees, provided that capital investments are organised centrally. There are also plans for NWSC to provide piped water services to rural growth centres (see https://www.nwsc.co.ug/). However, current sector funding levels suggest that a large expansion of piped water systems in rural areas will be difficult to achieve on a sustainable basis (WHO GLAAS Report, 2017, p. IX). An AMCOW Country Overview for 2015 and beyond for Uganda (WSP, 2011 p. 2) highlighted that Uganda, with its strong institutions has witnessed remarkable improvements in access but the low investment anticipated for the future may see these gains eroded.

Most people undoubtedly prefer the convenience of piped water supplies on their premises and are willing to pay for these services. This is evident from the 97 per cent customer bill payment or collection efficiency for NWSC piped connections (MWE, 2016, p. 47). However, many poorer households who reside in rural areas find it difficult to pay for on-plot piped water services, as is demonstrated by the fact that only 1 per cent of rural households have piped connections (WHO \& UNICEF, 2015, p. 75). The figure rises to 4 per cent when other on-plot options such as boreholes are added (WHO \& UNICEF, 2017, p. 75). Rural 
households are therefore likely to continue to rely on shared water sources for many years to come.

\section{Community water point services and stakeholder capacities in rural Uganda}

Hand-pumps are widely used for the rural poor in Africa as a cheaper and safer means of community drinking water sources, compared to many alternatives, but keeping hand-pumps functioning in the medium to longer term using community management continues to present major challenges. About 35 per cent of hand-pumps in Africa are not functioning at any one time (Rural Water Supply Network, 2009, p. 1), even though most countries in Africa have adopted the prevailing paradigm of Community Based Management Systems (CBMS) for achieving functional and reliable rural water supplies.

In Uganda, improvement in the functionality of rural water supplies increased to 88 per cent in 2014 but fell to 86 per cent in 2015, which is still below the expected targets set by the Government of Uganda of 90 per cent functionality. The fall in functionality is attributed to non-repair of broken-down facilities (MWE, 2016, p. 3). Furthermore, although functionality levels are better than the global picture, only 53 per cent of supplies are fully functional in that they provide an adequate and reliable yield throughout the day (MWE, 2011, p. vi), suggesting that the CBMS model is not delivering in its current form.

The prevailing school of thought in the literature is that the community management model has clear limitations and has failed to deliver expected levels of sustainability (Harvey, Uno, \& Reed, 2006, p. 183). Sustainable, community-based managed RWS continues to remain an elusive goal. Greater efforts are needed to test and evaluate alternative models for managing hand-pump water supplies (Foster, 2013, pp. 12037-12045).

A Sector Wide Approach (SWAp) in the Ugandan rural water sector has enabled 'the building of impressive government and donor alignment, harmonization, and coordination' (WSP, World Bank, 2011, p. 15). A number of challenges remain, according to the Ministry of Water and environment, as shown in Table 2.

Table 2. Main challenges to CBMS operation and maintenance systems and causes.

\begin{tabular}{|l|l|}
\hline \multicolumn{1}{|c|}{ Main Challenges } & \multicolumn{1}{|c|}{ Causes } \\
\hline $\begin{array}{l}\text { 1. More water users lose trust in } \\
\text { WSC }\end{array}$ & $\begin{array}{l}\text { Embezzlement of water fees by water and sanitation } \\
\text { committee (WSC) members. Also possible Illegal } \\
\text { intervention by politicians }\end{array}$ \\
\hline $\begin{array}{l}\text { 2. Water users come to expect } \\
\text { that water is free }\end{array}$ & $\begin{array}{l}\text { Water users whose distrust has grown refuse to pay } \\
\text { water fees and WSC cannot collect water fees on a } \\
\text { regular basis }\end{array}$ \\
\hline $\begin{array}{l}\text { 3. Caretaker retires, and no one is } \\
\text { left to take over }\end{array}$ & $\begin{array}{l}\text { WSC, which cannot collect water fees on a regular } \\
\text { basis, refuse to remunerate caretakers }\end{array}$ \\
\hline $\begin{array}{l}\text { 4. Hand pump parts gradually } \\
\text { suffer wear and tear and pump } \\
\text { discharge begins to decrease }\end{array}$ & $\begin{array}{l}\text { The absence of caretakers means that the hand pump } \\
\text { cannot be managed and preventive maintenance cannot } \\
\text { be done. }\end{array}$ \\
\hline $\begin{array}{l}\text { 5. Hand pumps breaks and cannot } \\
\text { be fixed promptly because WSC } \\
\text { have not saved for repairs }\end{array}$ & $\begin{array}{l}\text { Hand pumps cannot be promptly repaired when they } \\
\text { are broken because WSC with no regular collection of } \\
\text { water fees have not saved for maintenance expenses. } \\
\text { WSC lack sufficient funds for maintenance because } \\
\text { hand pumps break frequently }\end{array}$ \\
\hline 6. Hand pumps remain out of use & Water users' trust in water supply projects deteriorates \\
\hline
\end{tabular}




\begin{tabular}{|l|l|}
\hline $\begin{array}{l}\text { for long periods of time and water } \\
\text { users' trust in WSCs plummets } \\
\text { dramatically }\end{array}$ & $\begin{array}{l}\text { due to hand pumps breaking frequently or being out of } \\
\text { use frequently or for long periods }\end{array}$ \\
\hline $\begin{array}{l}\text { 7. Governments have little } \\
\text { financial power and cannot } \\
\text { respond to all requests for repairs } \\
\text { from WSCs }\end{array}$ & $\begin{array}{l}\text { Repairs become expensive because there is no choice } \\
\text { but to use private entities to perform them. } \\
\text { Very few conditional subsidies (DWSSCG) are granted }\end{array}$ \\
\hline $\begin{array}{l}\text { 8. Hand pumps cannot be } \\
\text { managed and preventive } \\
\text { maintenance cannot be done } \\
\text { because water fees are not being } \\
\text { collected regularly }\end{array}$ & $\begin{array}{l}\text { Caretakers to manage hand pumps cannot be hired } \\
\text { because WSC is unable to collect water fees on a } \\
\text { regular basis. } \\
\text { WSC do not understand the importance of preventive } \\
\text { maintenance because broken hand pumps can be used } \\
\text { again if they are repaired with government support. }\end{array}$ \\
\hline
\end{tabular}

Source: National annual water and sanitation sector performance report (MWE, 2016, p. 25).

O\&M is a key area in the search for sustainable RWS. Due to the limited success of the CBMS, a number of complementary and alternative models have emerged, an example being greater use of the local private sector, as part of Public Private Partnerships (PPPs). A number of hand-pump centered models have been developed in Uganda. We consider Hand Pump Mechanic Associations (HPMAs) in more detail here, as this approach has been scaled up in districts across Uganda.

The emergence of 'Community Management Plus' indicates the need to provide more professionalised services, such as the HPMA. The HPMA model has been incorporated in government policy and is being implemented throughout the country in at least 85 out of 108 districts surveyed, who now have registered HPMAs (MWE \& SNV, 2015, p. 5).

An early example of the development of an HPMA in 2005/06 was when WaterAid, an international UK-based charity, created an association of hand-pump mechanics in Katakwi district (Uganda). The main objectives were to improve the coordination of the work of the HPMs who undertake repairs, and enhance the credibility and quality assurance of the work done by the HPMs. The association supervises the work of the HPMs, supports them with transport, and reports to the districts. The districts provide the associations with office space and stationary, and organise training for all HPMs, while the water facilities are managed by the village water committees. The district council also monitors the HPMS and regulates charges for maintenance and repairs, to avoid exploitation of the communities. The districts concerned have seen an impressive increase in functionality and reduction of downtime of the hand pumps.

The field study of HPMAs by the authors examined the effectiveness and capacity of the HPMA model in five districts and was analysed according to four categories. HPMAs scored highest in technical capacity, poorly in financial management, with average ratings in management/leadership and operational/business capacity. These findings suggest that HPMAs have continued with the technical repair work that they have been carrying out for several years, but have been less inclined to adopt some of the more managerial and financial aspects of the HPMA model, possibly due to the lack of incentives put in place to expand their services. A key issue is the reluctance of communities to pay the HPMs for preventative 
maintenance, although it costs less in the long run, compared to paying for corrective maintenance when a more serious problem occurs.

The fact that 80 per cent of the case study HPMAs were able to perform complex rehabilitation tasks, such as fishing pipes out of the boreholes is indicative of how far they have come by learning from one another. Variations in scores between HPMAs can be attributed to several factors including longevity of the association, strength of the enabling environment, and availability of business opportunities (field interviews).

The HPMA approach has established some foundations that can potentially improve CMBS in the coming years. However, the model currently lacks a sufficiently supportive enabling environment if it is to become fully functional. Moreover, the focus on corrective repairs at the expense of preventative maintenance raises doubts over its sustainability.

Another approach being piloted is the 'Whave' PPP model which focuses on preventative maintenance and hence has better prospects of being more cost effective than purely corrective maintenance options. The Whave PPP model has been implemented in several districts in Uganda and involves working through local Water Service Providers (WSPs) who are individuals contracted by the Water Operator (in this case Whave Solutions) to provide O\&M services to a specific number of water points. The model is performance-based, focusing on preventive maintenance rather than repair. The WSPs earn money from a functioning water source rather than a broken-down water source.

The model has had significant impact on functionality rates, which, at 99 per cent is very encouraging. Nonetheless, some design issues with the Whave model need to be resolved if the model is to be introduced on a wider scale. The model is subsidised with Whave contributing about 40 per cent and the community 60 per cent of the total service cost. These models are promising and are being considered for future scaling up by the MWE and development partners. Meanwhile, the challenge of providing sustainable rural water services remains, despite extensive efforts to address these various issues as part of the Sector Wide Approach for water in Uganda. Government, donors and NGOs have previously focused rural water sector support on community-managed water sources. Who will provide sufficient resources and support for developing piped water systems in a sustainable manner as part of the drive to achieve SDG 6.1 is an outstanding question.

\section{Equity in service provision}

The SDG 6 targets for water supply emphasise 'universal access', which means for everyone. This is consistent with the overarching ambition of the 2030 Agenda to 'end poverty in all its forms' and 'leave no one behind' (WHO, 2017, p. 10). Analysis of the Ugandan data shows that only 4 per cent of the urban population have unimproved (potentially unsafe) main sources of water, whereas the percentage of the population using unimproved water supplies in rural areas was 24 per cent in 2015. Despite this significant reduction, many people are still facing public health risks due to the unsafe water that they drink (WHO \& UNICEF JMP, 2015a). Improving the water sources for those 24 per cent in rural areas with community shared water sources is clearly the priority, rather than providing more expensive piped water services.

Disaggregated data for per income quintile in 2012 for water supplies in Uganda show significant variations in equity. In urban areas, 60 per cent in the richest quintile, compared 
to only 5 per cent in the poorest quintile, had piped water on their premises (WHO \&UNICEF, 2015b). In rural areas only the richest quintile displayed a significant percentage of people with piped water on premises.

In the Uganda annual sector performance report (MWE, 2016, p. 26), equity of provision between areas is defined in terms of access to water points measured by calculating the standard deviation between the average numbers of persons per improved water point at subcounty level. The variation has changed from 243 persons per water point in 2007/08 to 142 in 2015/16, and is explained in part due to data entry problems. The trend is nevertheless encouraging. In the same annual report, the authors track gender equity against the Key Performance Indicator of per cent of Water User committees/Water Boards with women holding key positions. Performance against this target has risen to 86 per cent in 2016. Gender mainstreaming initiatives are thus found to have resulted in capacity building in 24 districts (MWE, 2016, p. 128).

Overall improvements have been made in the various dimensions of equity, in recent years. However, large gaps remain between urban and rural areas, in both Uganda and Sub-Saharan Africa. In particular, wide disparities are found in the provision of household piped water supplies, which are mainly confined to richer households, suggesting that provision of piped water supplies to poorer households (SDG 6.1) is likely to be hampered in the future due to affordability and poverty issues, particularly if sustainable services are to be provided.

\section{Discussion and conclusions}

Compared to many other African countries, Uganda has good capabilities for managing larger piped water systems effectively within both the national water utility and private sectors. However, limited incentives exist for managing small-scale rural piped water systems, where economies of scale are considerably less, and affordability is more of an issue in rural areas. A substantial increase in funding and support would be needed for new water infrastructure and sustainable management if the SDG targets are to be achieved. A key focus would also be needed on equity to provide and sustain piped water sources for poor communities.

In Sub-Saharan Africa (SSA) 68 per cent of the total population have 'improved water sources' compared to 79 per cent for Uganda (WHO \& UNICEF JMP, 2015, pp. 75, 77). Uganda is also performing better than most African countries in terms of 'transitioning to country-led service delivery pathways for water supply' according to AMCOW (2011). The challenges in improving water services in most SSA countries are greater than in Uganda, the more so since 'Aid commitments for water and sanitation to Sub-Saharan Africa have declined from US\$ 3.8 billion to US\$ 1.7 billion from 2012 to 2015' (WHO GLAAS Report, 2017, p. IX).

According to WHO \& UN-Water (2017, p. IX), National WASH budgets are increasing as countries prepare to take on board the SDGs. Yet discrepancies remain between global aspirations and national realities. More than 80 per cent of countries report insufficient financing to meet national WASH targets, let alone the higher levels of service that are the focus of the SDGs. 
The SDG emphasis on providing piped or on-plot water supplies for all households is recognised as a very ambitious long-term goal. For this reason, substantive support from donors and development partners for achieving fully functioning sustainable community water points will still be required for many years, particularly for poor rural areas. Due to the hitherto limited success of community-based management of shared water sources, a number of alternative 'Community Management Plus' approaches have emerged that support the local private sector in providing key inputs to enable sustainable outcomes.

Innovative institutional mechanisms and public-private-people partnerships will be needed to provide both sustainable piped water supplies and better management of shared community water supplies in rural areas of Sub-Saharan Africa. Such mechanisms are best developed based on a careful analysis of the lessons learnt and good practice in Uganda and elsewhere. The water SDGs provide sensible long-term aims for the types of services that most people prefer, but tracking of progress against the SDG's targets needs to be managed carefully. During the MDG period, the JMP regularly publicised which countries were on- or off-track against water and sanitation targets. However, this approach failed to account adequately for the considerable progress made by countries with low initial levels of human development, especially in Africa (UN, 2012, p. 7).

Publication of performance tracking against targets can provide incentives for policymakers, where the targets are feasible, but reliance on over-optimistic targets can have a demotivating effect among in-country stakeholders and create uncertainties around priorities. According to Coelho (2010, p. 406): 'Unrealistic optimism creates distortions which may be the most important source of efficiency loss in the economic system. When designing policy, governments often ignore this fact.'

How best then can we reconcile ambitious SDG targets with national realities? International performance reporting of progress against SDGs for piped water services in rural areas requires careful management, with less emphasis on simplistic on- and off-track reporting. The percentage increases in households with piped connections or similar indicators for each country could be a suitable indicator for constructive performance tracking.

Our analysis suggests that achievable medium-term country targets need to be given greater emphasis. A concise and robust method for medium-term target setting and review is critical, and is best achieved at national level, using realistic and systematic planning approaches. Balanced incentives seem to be necessary to encourage stakeholders to strive for realistic targets in the medium term, without demotivating countries with limited capacities and resources.

\section{References}

AMCOW (African Ministers Council on Water) (2011). AMCOW country status overviews regional synthesis report. Pathways to progress: Transitioning to country-led service delivery pathways to meet Africa's water supply and sanitation targets. Washington, DC: The World Bank. Retrieved from: http://www.wsp.org/wsp/content/pathways-progress-status-water-and-sanitation-africa.

Cuelo, P.M. (2010). Unrealistic optimism: Still a neglected trait. Journal of Business and Psychology. 25(3), 397-408. 
Foster, T. (2013). Predictors of sustainability for community-managed hand-pumps in SubSaharan Africa: Evidence from Liberia, Sierra Leone, and Uganda, Journal of Environmental Science \& Technology, |47(21), 12037-12046. Doi:.10.1021/es402086n

Hirn, M. (2013). Private sector participation in the Ugandan water sector: A review of 10 years of private management of small town water systems. Water and Sanitation Program: Working Paper, Nairobi: World Bank, retrieved from:

https://www.wsp.org/sites/wsp.org/files/publications/Private-Sector-Participation-in-theUgandan-Water-Sector-Review.pdf

Hutton, G. \& Chase, C. (2016). The knowledge base for achieving the Sustainable Development Goals targets on water supply, sanitation and hygiene, International journal of environmental research and public health, 13(6), E536, 1-35. doi: 10.3390/ijerph13060536.

Jarman J. (2016). Social inequality and its consequences in the twenty-first century, Journal of Contemporary Social Science, 11(2-3), 103-112, Doi: 10.1080/21582041.2016.1254277

Lockwood, H., Smits, S., Schouten, T., \& Moriarty, P., (2010). Providing sustainable water services at scale, International symposium on rural water services: Background paper. Retrieved from: https://www.ircwash.org/sites/default/files/Lockwood-2010-Providing.pdf

McIntosh, A. (2003). Asian water supplies: Reaching the urban poor, Mandaluyong City, Philippines: Asian Development Bank (ADB).

Ministry of Finance Planning and Economic Development, Uganda (2017). National Development Plan II has just been agreed for 2015-16 to 2019-20. Retrieved from http://www.gou.go.ug/ministry/ministry-finance-planning-and-economic-development.

Ministry of Water and Environment (2011). Assessment of the effectiveness of communitybased maintenance systems for rural water supply facilities, Directorate of Water Development, Ministry of Water and Environment, the Republic of Uganda.

Ministry of Water and Environment, Uganda (2016). Water and Environment Sector Performance Report, Kampala: Government of Uganda.

Ministry of Water and Environment, Uganda \& SNV (2015). National Assessment of District Hand Pump Mechanics Associations in Uganda. Draft Report II, Kampala.

Ndesamburo, J., Flynn E., \& French, S. (2012). Looking through an equity and inclusion lens in Tanzania: The experience of WaterAid, Gender \& Development, 20(3), 453-465. Doi: 10.1080/13552074.2012.731809

National Water and Sewerage Corporation (2015). NWSC Corporate Plan 2015-18. Retrieved from: https://www.nwsc.co.ug/files/corprateplan/NWSC_CORPORATE_PLAN_2015-2018

Reed, M.S., Fraser, E.D.G., Morse, S., \& Dougill, A.J. (2006). An adaptive learning process for developing and applying sustainability indicators with local communities. Ecological Economics Journal, 59(4), 406-418. Doi:10.1016/j.ecolecon.2005.11.008 
Rural Water Supply Network (RWSN)(2009). Hand-pump data in selected countries in SubSaharan Africa. Retrieved from

http://www.rural-water-supply.net/_ressources/documents/default/203.pdf United Nations (2012). Review of the contributions of the MDG Agenda to foster development: Lessons for the post-2015 UN Development Agenda, New York. Retrieved from:http://www.un.org/en/development/desa/policy/untaskteam_undf/group_a_mdg_assess $\underline{\text { ment.pdf }}$

UNDESA (2012). Sustainability Development Goals - Interactive timeline of post-2015 and post-Rio +20 processes? Retrieved from http://www.sustainabledevelopment2015.org/index.php/timeline

UNwater (2016). Integrated monitoring guide for SDG 6 targets and global indicators,. Retrieved from: http://www.unwater.org/app/uploads/2017/03/SDG-6-targets-and-globalindicators_2016-07-19.pdf

Van den Berg, C. \& Danilenko, A. (2017). Performance of water utilities in Africa. Washington, DC: World Bank.

Water and Sanitation Program, World Bank (2011). An AMCOW country status overview water supply and sanitation in Uganda - turning finance into services for 2015 and beyond. Retrieved from: http://documents.worldbank.org/curated/en/212801468111263063/Watersupply-and-sanitation-in-Uganda-turning-finance-into-services-for-2015-and-beyond

WHO (2017). Safely managed drinking water - thematic report on drinking water. Geneva: World Health Organization. Licence: CC BY-NC-SA 3.0 IGO.

World Health Organization \& UNICEF (2015a). Progress on sanitation and drinking water update, Joint Monitoring Programme, Geneva: World Health Organization.

WHO \& UNICEF (2015b). Estimates of use of water and sanitation facilities and by wealth quintile for Uganda. Retrieved from: https://www.wssinfo.org/data-estimates/

WHO \& UNICEF (2017a). Progress on Drinking Water, Sanitation and Hygiene: 2017 Update and SDG Baselines. Geneva: World Health Licence: CC BY-NC-SA 3.0 IGO.

WHO \& UN-Water (2017). Financing universal water, sanitation and hygiene under the Sustainable Development Goals, Report on Global Analysis and Assessment of Sanitation and Drinking-Water (GLAAS), Geneva: World Health Organization. 